\title{
PENGARUH PENGUASAAN KOSAKATA TERHADAP PEMAHAMAN ISI WACANA PADA SISWA KELAS V SD SE-KECAMATAN BANYUMAS TAHUN AJARAN 2020/2021
}

\author{
Ratna Handayani Pramukti ${ }^{1}$, Ngatman$^{2}$, Muhamad Chamdani ${ }^{3}$ \\ Universitas Sebelas Maret \\ ratnahandayanipramukti@student.uns.ac.id
}

\section{Article History}

accepted 1/11/2021

\begin{abstract}
The study aimed to determine the positive effect of vocabulary mastery on understanding the discourse to fifth grade students of public elementary schools in Banyumas Sub-district in academic year of 2020/2021 and to measure the contribution of vocabulary mastery on understanding the discourse to fifth grade students of public elementary schools in Banyumas Sub-district in academic year of 2020/2021. The research was correlational quantitative approach. Sampling technique was probability sampling cluster random sampling. Pearson Product Moment correlation analysis with results obtained correlation coefficient value of 0.579 and Sig value. $0,000<0.05$. It meant that vocabulary mastery gave positive and significant effect on understanding the discourse to fifth grade students of public elementary schools in Banyumas Sub-district in academic year of 2020/2021 and the correlation was moderate. Vocabulary mastery contributed $33.5 \%$ on understanding the discourse and the remaining $66.5 \%$ by other factors. It concludes that there is positive and significant effect of vocabulary mastery on understanding the discourse to fifth grade students of public elementary schools in Banyumas Sub-district in academic year of 2020/2021. The richer the mastery of student vocabulary, better the understanding of the content of discourse in students, and vice versa.
\end{abstract}

Keywords: vocabulary mastery, understanding, discourse

\begin{abstract}
Abstrak
Penelitian ini bertujuan membuktikan pengaruh positif penguasaan kosakata terhadap pemahaman isi wacana pada siswa kelas V SDN se-Kecamatan Banyumas tahun ajaran 2020/2021 dan menghitung besarnya sumbangan penguasaan kosakata terhadap pemahaman isi wacana pada siswa kelas V SDN se-Kecamatan Banyumas tahun ajaran 2020/2021. Pendekatan yang digunakan kuantitatif dengan metode korelasi. Pengambilan sampel dengan probability sampling jenis cluster random sampling. Analisis korelasi Pearson Product Moment dengan hasil diperoleh nilai koefisien korelasi sebesar 0,579 dan nilai Sig. 0,000<0,05, artinya penguasaan kosakata berpengaruh positif dan signifikan terhadap pemahaman isi wacana pada siswa kelas V SDN se-Kecamatan Banyumas tahun ajaran 2020/2021, tingkat korelasinya sedang. Sumbangan penguasaan kosakata terhadap pemahaman isi wacana, yaitu $33,5 \%$ sisanya $66,5 \%$ faktor lain. Kesimpulannya bahwa penguasaan kosakata berpengaruh positif dan signifikan terhadap pemahaman isi wacana pada siswa kelas V SDN se-Kecamatan Banyumas tahun ajaran 2020/2021. Semakin kaya penguasaan kosakata siswa, maka semakin baik pemahaman isi wacana pada siswa, begitu pula sebaliknya.
\end{abstract}

Kata kunci: penguasaan kosakata, pemahaman, isi wacana 


\section{PENDAHULUAN}

Keterampilan berbahasa memiliki beberapa aspek yang saling berkaitan. Berkaitan dengan aspek tersebut, Saddhono, Kundharu dan Slamet (2014: 5) menyebutkan bahwa keterampilan dasar berbahasa terdiri atas empat aspek, yaitu menyimak, berbicara, membaca, dan menulis. Dari keempat aspek keterampilan tersebut saling memiliki keterkaitan satu sama lain. Keterampilan membaca harus dimiliki siswa sedari dini minimal ketika awal memasuki bangku sekolah dasar. Di samping itu, bekal keterampilan membaca yang dimiliki siswa dilatarbelakangi adanya minat baca siswa yang mulai ditumbuhkan, sehingga minat baca siswa akan memengaruhi tingkat keterampilan membaca siswa. Dalam kegiatan membaca, pembaca dan teks konteks keduanya terlibat dalam pemahaman.

Pemahaman merupakan pokok dalam membaca untuk dapat menangkap makna. Menurut Sudijono (dalam Aprinawati, 2018: 142) pemahaman adalah kemampuan seseorang untuk mengerti atau memahami sesuatu setelah sesuatu itu diketahui dan diingat. Pemahaman memerlukan adanya pengetahuan kosakata serta maknanya. Sebagaimana menurut Maher Salah, 2008; Nation, 2001; Stahl, 1990 (dalam Anjomshoa dan Zamanian, 2014: 1) dalam International Journal on Studies in English Language and Literature yang mengemukakan bahwa "Vocabulary knowledge and reading comprehension are closely related, and this relationship is not onedirectional, since vocabulary knowledge can help the learner to comprehend written texts and reading can contribute to vocabulary growth". Artinya, pengetahuan kosakata dengan pemahaman membaca berkaitan erat dan hubungan tersebut tidak satu arah karena pengetahuan kosakata dapat membantu pembelajar untuk memahami teks tertulis dan membaca dapat berkontribusi pada pertumbuhan kosakata.

Pemahaman siswa terhadap bacaan dipengaruhi oleh faktor internal dan eksternal. Faktor internal yang memengaruhi, yaitu: (1) kemampuan kognitif; (2) pengetahuan bahasa; (3) pengalaman membaca; (4) minat membaca; (5) jangkauan mata; (6) perbendaharaan kosakata; (7) kecepatan interpretasi; (8) kemampuan intelektual; (9) keluwesan mengatur kecepatan. Sedangkan faktor eksternal yang memengaruhi, yaitu: (1) keluarga; (2) kebudayaan; (3) situasi. Untuk mengukur pemahaman dengan membaca dalam hati (senyap), yaitu membaca tanpa melafalkan apa yang dibaca agar dapat memahami isi teks bacaan dengan cermat dan tepat sehingga dapat diperoleh informasi dari teks bacaan yang dibaca. Keterampilan membaca membutuhkan penguasaan kosakata yang cukup agar dapat memahami yang dibaca.

Kosakata adalah khazanah kata yang penulis, pembicara, atau suatu bahasa miliki (Nurgiyantoro, 2014: 338). Selain itu, kosakata merupakan unsur bahasa yang mengandung seluruh informasi mengenai makna dan penggunaan kata dalam bahasa. Penguasaan kosakata berperan penting dalam pengembangan diri siswa. Cara berpikir dan tingkat kreativitas siswa dipengaruhi oleh penguasaan kosakata selama proses pembelajaran bahasa, sehingga kualitas siswa dalam 4 keterampilan berbahasa ditentukan oleh penguasaan kosakata (Kasno dalam Pramesti, 2015: 83). Penguasaan kosakata merupakan wahana yang berperan paling penting dalam berbahasa secara bebas sebagai alat komunikasi, baik secara lisan maupun tulisan. Dengan demikian, makin kaya kosakata yang dimiliki seseorang, maka makin besar pula kemungkinan ia terampil berbahasa. Dapat dikatakan seseorang yang memiliki kuantitas dan kualitas kosakata yang baik, kemungkinan ia memiliki kemampuan berbahasa yang baik pula. Penguasaan kosakata merupakan wahana yang berperan paling penting dalam berbahasa secara bebas sebagai alat komunikasi, baik secara lisan maupun tulisan. Dengan demikian, makin kaya kosakata yang dimiliki seseorang, maka makin besar pula kemungkinan ia terampil berbahasa.

Berdasarkan wawancara dengan guru kelas $\mathrm{V}$ yang dilakukan peneliti sebelum melakukan penelitian, sebagian besar siswa di SDN 3 Sudagaran dan SDN Kalisube, 
Kecamatan Banyumas, belum bisa menemukan sinonim dan antonim kata dalam suatu penggalan bacaan. Selain itu, pengetahuan siswa tentang makna kata kebanyakan siswa masih sebatas mengetahui makna dari kata yang familier, itu pun tidak semua kata yang familier siswa mengetahui makna katanya. Sebagaimana pendapat Djiwandono (dalam Viora, 2017: 156) yang mengatakan bahwa sinonim, antonim, dan makna kata merupakan indikator dalam penguasaan kosakata. Penguasaan kosakata siswa yang masih rendah juga disebabkan karena guru kurang memperdalam materi kosakata. Berdasarkan hal tersebut, maka dapat dikatakan bahwa perbendaharaan kata siswa masih rendah.

Perbendaharaan kata siswa yang masih rendah tersebut berdampak pada kemampuan memahami isi wacana pada siswa. Dilihat dari masih banyaknya siswa yang kurang memahami makna kata-kata dalam suatu wacana dan kesulitan dalam menemukan ide pokok paragraf dalam wacana. Selain hal tersebut, siswa juga masih kesulitan dalam menyimpulkan isi wacana. Sedangkan memahami makna dari suatu kata, menemukan ide pokok, dan menyimpulkan isi wacana merupakan 3 hal penting dari beberapa hal lain yang menentukan kemampuan memahami isi teks wacana dalam keterampilan membaca (Suhendar \& Supinah dalam Dalman, 2017: 9). Hal itu terlihat pada saat siswa mengerjakan soal latihan, mereka cenderung mengerjakan soal-soal yang lain terlebih dahulu daripada soal-soal mengenai pemahaman isi wacana. Hal ini dapat dikatakan bahwa masih rendahnya kemampuan siswa dalam memahami isi wacana.

Peneliti tertarik melakukan penelitian di Kecamatan Banyumas karena Banyumas terkenal dengan bahasa daerah Jawa yang digunakan, yaitu dialek Banyumasan yang sering disebut bahasa ngapak. Logat bahasanya agak berbeda dibanding dengan dialek bahasa Jawa yang lain. Bahasa Banyumasan populer dengan cara bicaranya yang khas. Dialek ini disebut Banyumasan sebab dimiliki dan dipakai oleh warga yang tinggal di daerah Banyumasan serta karisidenan Banyumas yang meliputi Kabupaten Cilacap, Kabupaten Kebumen, Kabupaten Purbalingga, serta Kabupaten Banjarnegara, terlebih lagi hingga Kabupaten Tegal serta Brebes. Melihat kentalnya penggunaan bahasa ngapak oleh masyarakat Banyumas, tentu pada sebagian masayarakat Banyumas, yaitu pada siswa sekolah dasar memiliki banyak perbendaharaan kosakata bahasa daerahnya. Hal ini karena kebanyakan siswa sekolah dasar di Kecamatan Banyumas menjadikan bahasa daerah atau bahasa ngapak sebagai bahasa pertama. Sedangkan bahasa Indonesia sebagai bahasa kedua, sehingga perbendaharaan kosakata bahasa Indonesia lebih sedikit dibandingakan kosakata bahasa daerahnya. Padahal dengan kaya akan perbendaharaan kosakata bahasa Indonesia akan dapat memudahkan siswa dalam memahami sebuah isi sesuatu yang dibaca termasuk isi teks wacana.

Berdasarkan uraian di atas, dalam penelitian ini dapat dirumuskan masalah, sebagai berikut: (1) Apakah terdapat pengaruh positif penguasaan kosakata terhadap pemahaman isi wacana pada siswa kelas V SDN se-Kecamatan Banyumas tahun ajaran 2020/2021? ; (2) Berapa besar sumbangan penguasaan kosakata terhadap pemahaman isi wacana pada siswa kelas V SDN se-Kecamatan Banyumas tahun ajaran 2020/2021?

Adapun tujuan dari penelitian ini, yaitu untuk membuktikan adanya pengaruh positif penguasaan kosakata terhadap pemahaman isi wacana pada siswa kelas $\mathrm{V}$ SDN se-Kecamatan Banyumas tahun ajaran 2020/2021 dan menghitung seberapa besar sumbangan penguasaan kosakata terhadap pemahaman isi wacana pada siswa kelas V SDN se-Kecamatan Banyumas tahun ajaran 2020/2021. 


\section{METODE}

Penelitian ini menggunakan pendekatan kuantitatif dengan metode penelitian korelasi. Variabel pada penelitian ini terdiri dari variabel bebas, yaitu penguasaan kosakata $(X)$ dan variabel terikat, yaitu pemahaman isi wacana pada siswa kelas $V \mathrm{SD}$ (Y). Populasi dalam penelitian ini, yaitu seluruh siswa kelas V SDN se-Kecamatan Banyumas tahun ajaran 2020/2021 yang berjumlah 803 siswa yang terdiri dari 31 sekolah dasar. Sampel 10 SDN di Kecamatan Banyumas, Kabupaten Banyumas. Teknik pengambilan sampel dengan probability sampling jenis cluster random sampling dengan jumlah sampel sebanyak 270 siswa.

Teknik pengumpulan data dalam penelitian ini dengan tes penguasaan kosakata dan pemahaman isi wacana pada siswa kelas $V$ SD.Tes berupa soal pilihan ganda materi Bahasa Indonesia tentang kosakata kelas V SD sebanyak 31 soal dan materi teks wacana muatan pelajaran Bahasa Indonesia kelas V SD semester 1 sebanyak 29 soal.

Berdasarkan uji validitas tes uji coba penguasaan kosakata dan pemahaman isi wacana yang dianalisis menggunakan aplikasi SPSS versi 25, diketahui dari kedua macam tes 40 butir soal yang dibuat terdapat 31 butir soal penguasaan kosakata yang valid dan 29 butir soal pemahaman isi wacana yang valid. Reliabilitas instrumen dihitung menggunakan rumus Cronbach's Alpha. Hasil uji reliabilitas tes uji coba sebesar 0,865 penguasaan kosakata dan 0,898 pemahaman isi termasuk kategori reliabel sangat tinggi.

Uji prasyarat analisis pada penelitian ini untuk uji korelasi dan regresi menggunakan uji normalitas data dan linieritas. Kemudian data akan dianalisis menggunakan analisis korelasi sederhana dan sumbangan efektif (SE). Analisis korelasi sederhana (correlation bivariate) digunakan untuk mengetahui hubungan antara dua variabel (Priyatno, 2012: 59-60). Analisis korelasi yang digunakan, yaitu analisis korelasi Pearson Product Moment. Untuk mencari nilai koefisien korelasi, peneliti menggunakan rumus korelasi Pearson Product Moment menurut Sugiyono (2016: 183) sebagai berikut:

$$
r_{x y}=\frac{\left.n \sum X Y-\left(\sum X\right)\left(\sum Y\right)\right)}{\sqrt{\left.\left\{n \sum X^{2}-\left(\sum X\right)^{2}\right\} n \sum Y^{2}-\left(\sum Y\right)^{2}\right\}}}
$$

Bentuk hipotesis analisis korelasi penelitian ini sebagai berikut:

$\mathrm{H}_{0}: \rho=0$ $=0$ berarti tidak ada pengaruh

$\mathrm{H}_{1}: \rho \neq 0$

$\neq 0$ berarti ada pengaruh lebih kecil atau lebih besar dari nol, artinya terdapat pengaruh penguasaan kosakata terhadap pemahaman isi wacana.

Kriteria pengujian (berdasarkan signifikansi) yaitu:

Jika signifikansi $>0,05$, maka terima $\mathrm{HO}$

Jika signifikansi $<0,05$, maka tolak $\mathrm{HO} \rightarrow$ a yang digunakan yaitu $5 \%$ atau 0,05 .

Penelitian ini juga menganalisis sumbangan efektif, namun diperlukan mencari beberapa analisis, yaitu koefisien determinasi dan sumbangan relatif.

$$
\begin{aligned}
& \mathrm{SE}=(\mathrm{SR}) \times\left(\mathrm{R}^{2}\right) \\
& \text { Keterangan: } S E=\text { sumbangan efektif } \\
& \mathrm{SR}=\text { sumbangan relatif } \\
& \mathrm{R}^{2}=\text { koefisien determinasi }
\end{aligned}
$$

\section{Hasil Penelitian}

\section{HASIL DAN PEMBAHASAN}

Dalam penelitian ini menggunakan data yang berasal dari skor tes penguasaan kosakata dan pemahaman isi wacana pada siswa kelas V SD. Data penguasaan kosakata dan pemahaman isi wacana pada penelitian ini diperoleh dari skor tes penguasaan kosakata dan tes pemahaman isi wacana, kemudian ditabulasi 
menggunakan bantuan Microsoft Office Excel yang selanjutnya diolah menggunakan aplikasi SPSS versi 25 untuk dianalisis secara deskriptif.

Tabel 1. Hasil Analisis Deskriptif Data Penguasaan Kosakata

Statistics

\begin{tabular}{|c|c|}
\hline \multicolumn{2}{|l|}{ Penguasaan Kosakata } \\
\hline \multicolumn{2}{|l|}{$\mathrm{N} \quad$ Valid } \\
\hline Missing & 0 \\
\hline Mean & 24.5296 \\
\hline Std. Error of Mean & .30289 \\
\hline Median & 25.5 \\
\hline Mode & 29 \\
\hline Std. Deviation & 4.97700 \\
\hline Variance & 24.770 \\
\hline Skewness & -.801 \\
\hline Std. Error of Skewness & 148 \\
\hline Kurtosis & -.037 \\
\hline Std. Error of Kurtosis & .295 \\
\hline Range & 21 \\
\hline Minimum & 10 \\
\hline Maximum & 31 \\
\hline Sum & 6623 \\
\hline
\end{tabular}

Data penguasaan kosakata diharapkan berdistribusi normal karena memiliki nilai mean, median, modus yang hampir sama. Jika dilihat dari perhitungan rasio skewness, yaitu $-0,801$ dan rasio kurtosis, yaitu $-0,037$, maka data penguasaan kosakata berdistribusi normal karena terletak di antara nilai -2.00 sampai dengan 2.00.

Tabel 2. Hasil Analisis Deskriptif Data Pemahaman Isi Wacana

\section{Statistics}

\begin{tabular}{lr}
$\begin{array}{lr}\text { Pemahaman Isi Wacana } \\
\mathrm{N}\end{array}$ & \begin{tabular}{r} 
Valid \\
\cline { 2 - 3 }
\end{tabular} \\
\hline Missing & 0 \\
\hline Mean & 21.4296 \\
\hline Std. Error of Mean & .29424 \\
\hline Median & 23 \\
\hline Mode & 23 \\
\hline Std. Deviation & 4.83488 \\
\hline Variance & 23.376 \\
\hline Skewness & -.640 \\
\hline Std. Error of Skewness & .148 \\
\hline Kurtosis & -.489 \\
\hline Std. Error of Kurtosis & .295 \\
\hline Range & 21 \\
\hline Minimum & 8 \\
\hline Maximum & 29 \\
\hline Sum & 5786 \\
\hline
\end{tabular}

Data pemahaman isi wacana diharapkan berdistribusi normal karena memiliki nilai mean, median, modus yang hampir sama. Jika dilihat dari perhitungan rasio skewness, yaitu $-0,640$ dan rasio kurtosis, yaitu $-0,489$, maka data pemahaman isi wacana berdistribusi normal karena terletak di antara nilai -2.00 sampai dengan 2.00. 
Uji prasyarat penelitian ini, yaitu uji normalitas dan uji linieritas. Berdasarkan uji normalitas penguasaan kosakata, diperoleh hasil pada kolom Kolmogorov-Smirnov dengan nilai Sig., yaitu 0,150, sehingga dapat diketahui bahwa signifikansi $0,150>$ 0,05 . Oleh karena itu, dapat disimpulkan bahwa $H_{0}$ diterima, artinya variabel penguasaan kosakata berasal dari populasi yang berdistribusi normal. Hasil uji normalitas pemahaman isi wacana pada kolom Kolmogorov-Smirnov dengan nilai Sig., yaitu 0,073 , sehingga dapat diketahui bahwa signifikansi $0,073>0,05$. Oleh karena itu, dapat disimpulkan bahwa $\mathrm{H}_{0}$ diterima, artinya variabel pemahaman isi wacana berasal dari populasi yang berdistribusi normal. Hasil uji linieritas diperoleh nilai Sig. value Deviation from Linearity, yaitu 0,016, sehingga dapat diketahui bahwa signifikansi $0,016>0,05$. Oleh karena itu, dapat disimpulkan bahwa $\mathrm{H}_{0}$ diterima, artinya terdapat pengaruh linier penguasaan kosakata terhadap pemahaman isi wacana pada siswa kelas $\mathrm{V}$ SD.

Uji korelasi yang telah dilakukan menggunakan analisis korelasi Pearson Product Moment dengan bantuan aplikasi SPSS versi 25 menunjukkan bahwa nilai signifikansi (1-tailed) pada penelitian ini, yaitu 0,579, sehingga nilai $p$ value, yaitu 0,579 >0,05. Artinya $\mathrm{H}_{0}$ ditolak, artinya ada pengaruh positif dan signifikan penguasaan kosakata terhadap pemahaman isi wacana.

Tabel 3. Hasil Analisis Korelasi Penguasaan Kosakata dan Pemahaman Isi Wacana

\section{Correlations}

\begin{tabular}{llr|r} 
& & $\begin{array}{c}\text { Pemahaman } \\
\text { Isi Wacana }\end{array}$ & $\begin{array}{r}\text { Penguasaaa } \\
\text { n Kosakata }\end{array}$ \\
\hline \multicolumn{1}{c}{$\begin{array}{l}\text { Pemahaman Isi } \\
\text { Wacana }\end{array}$} & $\begin{array}{l}\text { Pearson } \\
\text { Correlation }\end{array}$ & 1 & $.579^{* *}$ \\
\cline { 2 - 4 } & Sig. (1-tailed) & 270 & .000 \\
\cline { 2 - 4 } & $\mathrm{N}$ & $.579^{* *}$ & 270 \\
\hline $\begin{array}{l}\text { Penguasaaan } \\
\text { Kosakata }\end{array}$ & $\begin{array}{l}\text { Pearson } \\
\text { Correlation }\end{array}$ & .000 & 1 \\
\cline { 2 - 4 } & Sig. (1-tailed) & 270 & 270 \\
\cline { 2 - 4 } & $\mathrm{N}$ & & \\
\hline${ }^{* *}$. Correlation is significant at the 0.01 level (1-tailed). &
\end{tabular}

\section{Pembahasan}

Hasil pengujian hipotesis menggunakan aplikasi SPSS versi 25 didapatkan nilai koefisien korelasi antara penguasaan kosakata dan pemahaman isi wacana pada siswa kelas V SD sebesar 0,579 dengan nilai Sig. (1-tailed), yaitu 0,000. Nilai Sig. $0,000<0,05$ berarti hipotesis penelitian ini dapat diterima, sehingga dapat ditarik kesimpulan bahwa penguasaan kosakata berpengaruh positif dan signifikan terhadap pemahaman isi wacana pada siswa kelas V SDN se-Kecamatan Banyumas tahun ajaran 2020/2021. Hasil penelitian ini hampir sejalan dengan penelitian yang telah dilakukan oleh Susilawati dan Suhardi (2016: 120) karena sama-sama menggunakan variabel penguasaan kosakata. Hasil penelitian tersebut menyatakan terdapat hubungan positif dan signifikan antara penguasaan kosakata dan menemukan gagasan secara bersama-sama dengan keterampilan membaca pemahaman dengan $R$ sebesar $0,651, R^{2}$ sebesar 0,424 , dan adjusted $R$ square sebesar 0,420 dengan signifikansi $\rho<0,05$.

Hasil analisis koefisien korelasi antara variabel penguasaan kosakata dan pemahaman isi wacana, yaitu 0,579. Berdasarkan pendapat Sugiyono (2016: 231) mengenai pedoman interpretasi terhadap koefisien korelasi menyatakan bahwa koefisien korelasi pada penelitian ini yaitu 0,579 berada pada tingkat hubungan sedang yang berarti pengaruhnya cukup kuat, sedangkan nilai koefisien korelasi positif menunjukkan hubungan yang searah. Korelasi akan lebih kuat jika mendekati angka 1. 
Hasil penelitian ini hampir sejalan dengan penelitian yang telah dilakukan oleh Anjomshoa dan Zamanian (2014: 94) mengenai pengaruh penguasaan kosakata yang menyatakan bahwa "There was a significant positive relationship between vocabulary knowledge and reading comprehension. $(r=0,599)$, implying that a larger vocabulary enabled students to recall more information from the text they read and also deeper knowledge of words help learners comprehend the text better." Ada hubungan positif dan signifikan antara pengetahuan kosakata dan pemahaman membaca ( $r=0.599)$, menyiratkan bahwa kosakata yang lebih besar memungkinkan siswa mengingat lebih banyak informasi dari teks yang dibaca dan pengetahuan yang lebih mendalam tentang kosakata membantu pelajar memahami teks dengan lebih baik.

Sumbangan penguasaan kosakata terhadap pemahaman isi wacana pada penelitian ini diperoleh dengan menghitung sumbangan efektif. Sebelum mencari sumbangan efektif, peneliti mencari nilai koefisien determinasi dan sumbangan relatif terlebih dahulu. Nilai sumbangan relatif diperoleh setelah peneliti menemukan nilai JK reg, b dan jumlah xy. Aplikasi SPSS versi 25 digunakan untuk mencari nilai JK reg dan nilai b dengan menggunakan analisis regresi, sedangkan aplikasi MS. Excel digunakan untuk mencari jumlah xy.

Hasil perhitungan sumbangan efektif pada variabel penguasaan kosakata dan pemahaman isi wacana diperoleh hasil sebesar $33,5 \%$, artinya penguasaan kosakata yang dimiliki siswa dapat berperan dalam meningkatkan pemahaman isi wacana sebesar $33,5 \%$ dan sisanya sebesar $66,5 \%$ dipengaruhi oleh faktor lain seperti faktor internal, yaitu kemampuan kognitif, pengalaman membaca, minat membaca, jangkauan mata, kecepatan interpretasi, dan kemampuan intelektual. Sedangkan faktor lain dari eksternal yang memengaruhi, yaitu faktor keluarga, kebudayaan, dan situasi. Hasil sumbangan efektif pada penelitian ini sesuai dengan penelitian Ramdhan (2017: 244) yang menyatakan bahwa sumbangan penguasaan kosakata dalam meningkatkan pemahaman membaca teks narasi sebesar 21,89\%. Artinya penguasaan kosakata bukan satu-satunya faktor yang menyebabkan meningkatnya pemahaman membaca teks narasi.

\section{SIMPULAN}

Berdasarkan hasil penelitian dan pembahasan mengenai pengaruh penguasaan kosakata terhadap pemahaman isi wacana pada siswa kelas V SDN seKecamatan Banyumas tahun ajaran 2020/2021 dapat ditarik kesimpulan bahwa terdapat pengaruh positif dan signifikan penguasaan kosakata terhadap pemahaman isi wacana pada siswa kelas V SDN se-Kecamatan Banyumas tahun ajaran 2020/2021 ditunjukkan dari perolehan nilai koefisien korelasi sebesar 0,579 dan nilai Sig. (1-tailed) 0,000 dengan tingkat korelasi sedang. Sumbangan efektif variabel penguasaan kosakata terhadap pemahaman isi wacana, yaitu 35,5\%, artinya penguasaan kosakata dapat berperan dalam meningkatkan pemahaman isi wacana pada siswa kelas V SD sebesar $33,5 \%$ dan sisanya sebesar $66,5 \%$ dipengaruhi oleh faktor lain. Diharapkan peneliti selanjutnya dapat mengkaji lebih lanjut mengenai penguasaan kosakata dan pemahaman isi wacana atau mencari referensi lain agar hasil penelitian jauh lebih baik.

\section{DAFTAR PUSTAKA}

Amzani, A. A., Lee, J., \& Relmasira, S. C. (2017). Upaya Peningkatan Kemampuan Pemahaman Membaca Siswa melalui Metode Global Berbantuan Media Gambar dan Alat Peraga pada Siswa Kelas I SD. Jurnal Handayani PGSD FIP Unimed, 7(2), 131-136.

Anjomshoa, L., \& Zamanian, M. (2014). The Effect of Vocabulary Knowledge on

Reading Comprehension of Iranian EFL Learners in Kerman Azad 
University. International Journal on Studies in English Language and Literature (IJSELL), 2(5), 90-95.

Aprinawati, I. (2018). Penggunaan Model Peta Pikiran (Mind Mapping) untuk Meningkatkan Pemahaman Membaca Wacana Siswa Sekolah Dasar. Jurnal Basicedu, 2(1), 140-147.

Dalman. (2017). Keterampilan Membaca. Jakarta: PT Raja Grafindo Persada.

Nurgiyantoro, B. (2014). Penilaian Pembelajaran Bahasa Berbasis Kompetensi. Yogyakarta:BPFE-Yogyakarta.

Pendidikan, M. (2016). Peraturan Menteri Pendidikan dan Kebudayaan Republik Indonesia Nomor 21 Tahun 2016 tentang Standar Isi Pendidikan Dasar dan Menengah. Jakarta: Menteri Pendidikan dan Kebudayaan Republik Indonesia.

Pramesti, U. D. (2015). Peningkatan Penguasaan Kosakata Bahasa Indonesia dalam Keterampilan Membaca melalui Teka-Teki Silang (Penelitian Tindakan di Kelas VI SDN Surakarta 2, Kecamatan Suranenggala, Kabupaten Cirebon, Jawa Barat). Puitika, 11 (1), 82-93.

Priyatno, D. (2012). Belajar Cepat Olah Data Statistik dengan SPSS. Yogyakarta: CV. Andi Offset.

Ramdhan, V. (2017). Pengaruh Penguasaan Kosakata dan Tata Bahasa terhadap Pemahaman Membaca Teks Narasi Bahasa Inggris. DEIKSIS, 9(02), 240-246.

Saddhono, Kundharu, dan Slamet. (2014). Pembelajaran Keterampilan Berbahasa Indonesia Teori dan Aplikasi Edisi 2. Yogyakarta: Graha IImu.

Sugiyono. (2016). Metode Penelitian Kuantitatif Kualitataif dan Kombinasi (Mixed Methods). Bandung: Alfabeta.

Susilawati, T. M., \& Suhardi, S. (2016). Hubungan Antara Penguasaan Kosakata dan Ketepatan Menemukan Gagasan dengan Keterampilan Membaca Pemahaman. LingTera, 3(1), 112-121.

Viora, D. (2017). Kontribusi Penguasaan Kosakata terhadap Kemampuan Membaca Pemahaman Siswa Kelas XI SMA Negeri I Kuok Kabupaten Kampar Provinsi Riau. School Education Journal PGSD FIP Unimed, 7(2), 154-163. 